\title{
Better contralateral breast cancer risk estimation and alternative options to contralateral prophylactic mastectomy
}

This article was published in the following Dove Press journal:

International Journal of Women's Health

4 February 2015

Number of times this article has been viewed

\author{
Kalatu R Davies' \\ Scott B Cantor' \\ Abenaa M Brewster ${ }^{2}$ \\ 'Department of Health Services \\ Research, ${ }^{2}$ Department of Clinical \\ Cancer Prevention, The University \\ of Texas MD Anderson Cancer \\ Center, Houston, TX, USA
}

\begin{abstract}
The incidence of contralateral prophylactic mastectomy (CPM) has increased among women with breast cancer, despite uncertain survival benefit and a declining incidence of contralateral breast cancer (CBC). Patient-related reasons for undergoing CPM include an overestimation of the risk of $\mathrm{CBC}$, increased cancer worry, and a desire to improve survival. We summarize the existing literature on $\mathrm{CBC}$ risk and outcomes and the clinical benefit of CPM among women with unilateral breast cancer who have a low-to-moderate risk of developing a secondary cancer in the contralateral breast. Published studies were retrieved from the MEDLINE database with the keywords "contralateral breast cancer" and "contralateral prophylactic mastectomy". These include observational studies, clinical trials, survival analyses, and decision models examining the risk of $\mathrm{CBC}$, the clinical and psychosocial effects of CPM, and other treatment strategies to reduce $\mathrm{CBC}$ risk. Studies that have evaluated $\mathrm{CBC}$ risk estimate it to be approximately $0.5 \%$ annually on average. Patient-related factors associated with an increased risk of $\mathrm{CBC}$ include carriers of $B R C A 1 / 2$ mutations, young age at breast cancer, and strong family history of breast cancer in the absence of a $B R C A 1 / 2$ mutation. Although CPM reduces the risk of $\mathrm{CBC}$ by approximately $94 \%$, it may not provide a significant gain in overall survival and there is conflicting evidence that it improves disease-free survival among women with breast cancer regardless of estrogen receptor (ER) status. Therefore, alternative strategies such as the use of tamoxifen or aromatase inhibitors, which reduce the risk of $\mathrm{CBC}$ by approximately $50 \%$, should be encouraged for eligible women with ER-positive breast cancers. Future research is needed to evaluate the impact of decision and educational tools that can be used for personalized counseling of patients regarding their $\mathrm{CBC}$ risk, the uncertain role of $\mathrm{CPM}$, and alternative $\mathrm{CBC}$ risk reduction strategies.
\end{abstract}

Keywords: contralateral prophylactic mastectomy, contralateral breast cancer, endocrine therapy, sporadic breast cancer, risk assessment

\section{Introduction}

For women with unilateral breast cancer, removal of the contralateral, cancer-free breast (contralateral prophylactic mastectomy, CPM) is a surgical option that has increased in frequency, despite uncertain survival benefit ${ }^{1-3}$ and a declining incidence of contralateral breast cancer (CBC). The increasing use of CPM as a breast cancer preventative treatment ${ }^{4}$ indicates a need for better estimation of the risk of $\mathrm{CBC}$ and knowledge of alternative $\mathrm{CBC}$ risk reduction treatment options for improved clinical decision-making.

Despite the increase in use of adjuvant endocrine therapy for women with estrogen receptor (ER)-positive tumors that reduces the risk of $\mathrm{CBC}$ by approximately $50 \%$, the CPM rate has continued to escalate as a management therapy to prevent 
the development of cancer in the healthy breast. ${ }^{2}$ Although CPM may improve health outcomes for particular subgroups, specifically younger women with a $B R C A 1 / 2$ mutation or those with a strong family history of breast cancer, the additional surgery may be unnecessary for the majority of women diagnosed with breast cancer. ${ }^{5,6}$ In part, the increasing use of CPM may be due to treatment choices related to the index cancer such as desire for bilateral reconstruction or unsuccessful breast conservation rather than an increased risk of developing $\mathrm{CBC}$. ${ }^{7,8}$ Specific factors associated with having CPM in unselected patients include undergoing genetic testing, age, ethnicity, family history, and improved reconstruction options. ${ }^{9,10}$

Women with a family history of breast cancer, ERnegative tumors, and younger age at breast cancer diagnosis have the greatest risk for CBC. ${ }^{11,12}$ In 1993, the Society of Surgical Oncology published guidelines for indications for CPM with an update issued in 2007. These include: 1) BRCA1/2 mutation or a family history of breast or ovarian cancer in multiple first-degree relatives, 2) difficult surveillance because of high mammographic breast density or indeterminate calcifications, and 3 ) desire for improved symmetry or bilateral breast reconstruction. ${ }^{13}$ Since $\mathrm{CBC}$ rates in high-risk groups have not increased over time, patients without the aforementioned indications that elect to undergo CPM, may view prophylactic surgery as beneficial for other reasons, particularly when mastectomy is required for the primary breast cancer. Indeed, Rosenberg et al $^{14}$ showed in a retrospective study of women with breast cancer that the reasons for CPM included the desire to reduce the risk of $\mathrm{CBC}$, to improve survival, and to have peace of mind. In addition, an increased willingness of surgeons to respect their patient's preferences may contribute to the increase in CPM.

The aim of this review is to summarize the risk of $\mathrm{CBC}$ from published studies to guide patients and clinicians on the best treatment options for reducing $\mathrm{CBC}$, which may include CPM or other alternatives. We focus on women with unilateral breast cancer who have a low-to-moderate risk of developing a secondary cancer in the contralateral breast. We examine the role of CPM, alternative risk reduction strategies for $\mathrm{CBC}$ and the need for future studies to evaluate the impact of decision-making and educational tools for personalized counseling of $\mathrm{CBC}$ risk.

\section{Methods}

We retrieved published studies from the MEDLINE database using the keywords "contralateral breast cancer" or "contralateral prophylactic mastectomy". We inspected the reference lists of identified articles published in English for further relevant articles. Any study within the last 15 years or seminal studies that evaluated the risk of $\mathrm{CBC}$ and/or survival, the clinical benefit of CPM, or alternative treatment options for preventing $\mathrm{CBC}$ or recurrence of index cancer were considered. Studies were examined for relevancy, patient cohort, methodology, and the summary of clinical outcomes, eg, risk of CBC, disease-free survival (DFS), overall survival (OS), and quality-adjusted life expectancy (QALY). These include observational studies, review papers, randomized controlled trials, survival analyses, and decision models.

\section{Results}

\section{Incidence and outcomes of CBC}

$\mathrm{CBC}$ is the most common second primary cancer in breast cancer patients, accounting for between $30 \%$ and $50 \%$ of all second cancers. ${ }^{15-17}$ Commonly cited are studies that assess the annual risk of developing a CBC to be $0.5 \%-0.75 \%{ }^{5,18-23}$ However, this may be an overestimate due to the now widespread use of adjuvant systemic therapy. In a meta-analysis performed by the Early Breast Cancer Trialists' Collaborative Group (EBCTCG), the 15-year incidence of CBC was $6.5 \%$ in women with ER-positive disease who were randomized to no tamoxifen and approximately $7.1 \%$ in women with ER-negative disease regardless of use of tamoxifen. ${ }^{24}$ In a study using the Surveillance, Epidemiology, and End Results (SEER) database (1975-2006), Nichols et $\mathrm{al}^{4}$ showed a decline in CBC incidence from 1990 to 2006 driven by declines in $\mathrm{CBC}$ rates in patients who had ER-positive tumors. In comparison, ER-negative tumors were associated with higher rates and there were no clear declines. There were also age-specific peaks at 30 and 70 years.

A study of the SEER database (1973-1996) found that CBC occurred in $4.2 \%$ of patients with a median follow-up time of 4.5 years $(0.25-23.6$ years). The $5,10,15$, and 20 -year actuarial incidence rates of $\mathrm{CBC}$ were $3 \%, 6.1 \%$, $9.1 \%$, and $12 \%$, respectively. Increased risk of $\mathrm{CBC}$ was associated with medullary carcinoma, black race, receiving radiotherapy and surviving more than 5 years after the index cancer, and age greater than 55 years at diagnosis. These specific findings of high-risk patient subgroups may have implications for the management of breast cancer patients after initial treatment. ${ }^{15}$

Prognostic significance of $\mathrm{CBC}$ was evaluated by Schaapveld et $\mathrm{al}^{17}$ in a population-based study of Stage I-IIIA patients diagnosed in the Netherlands between 1989 and 2002 with a median follow-up time of 5.8 years. The results indicated that a higher metachronous $\mathrm{CBC}$ risk 
(CBC diagnosed more than 6 months from initial diagnosis) was observed among women younger than 40 years of age and that it was associated with poorer survival, emphasizing the need for long-term surveillance for that patient group. The use of endocrine therapy and chemotherapy significantly reduced the incidence of metachronous CBC.

In order to evaluate the contribution of $\mathrm{CBC}$ in impacting overall survival, Quan et $\mathrm{al}^{13}$ utilized the Oregon State Cancer Registry SEER data during the period 1996-2004, and compared the incidence and overall survival between women with a synchronous breast cancer (CBC diagnosed within 12 months of the first primary breast cancer) and those with a metachronous breast cancer (CBC diagnosed greater than 12 months after the first primary breast cancer). ${ }^{11}$ The study by Quan et $\mathrm{al}^{13}$ showed an incidence rate of $2.1 \%$ for synchronous $\mathrm{CBCs}$ and $1.2 \%$ for the metachronous $\mathrm{CBCs}$. The mean age of diagnosis of initial cancers was 63.8 years, and mean time interval between diagnoses was 40.5 months for metachronous breast cancer. The mean annual incidence rate of $\mathrm{CBC}$ was $0.13 \%$. This $\mathrm{CBC}$ incidence rate was lower than estimates from earlier studies conducted before the widespread use of adjuvant therapies ${ }^{7,23,25}$ which have found an average annual incidence of $0.7 \%-1.8 \%$. Among patients with an initial Stage I or II cancer, $98.7 \%$ and $86.8 \%$ of the CBCs, respectively, were Stage II or better. Those with local tumors (DCIS, stage 1) had a slightly lower 5-year survival rates $(95.5 \%$ compared to $97.5 \%)$ and much lower 10 -year survival (76.4\% compared to $93.5 \%$ ) than similar staged patients in the SEER database (1998-2003). Synchronous $\mathrm{CBC}$ patients had a $10 \%$ lower survival than metachronous $\mathrm{CBC}$ patients, perhaps associated with higher mean stage of synchronous CBCs. ${ }^{13}$ Previous results from other studies evaluating the association between synchronicity and survival have been mixed. In a study of a prospectively accrued database in a UK general district hospital (1963-1999), Carmichael et $\mathrm{a}^{26}$ showed a worse survival prognosis with synchronous $\mathrm{CBC}$ than with metachronous or unilateral breast cancer. In a study of the Geneva cancer registry (1970-2002), Verkooijen et $\mathrm{al}^{27}$ did not find a significant increase in mortality risk for synchronous bilateral compared to metachronous bilateral cancers. A recent review by $\mathrm{Narod}^{28}$ estimated an annual risk of $0.3 \%-0.8 \%$ noting that $\mathrm{CBC}$ risk may depend on certain factors, including patient-specific factors such as, young age at diagnosis, family history, tumor type, lobular histology, and BRCA1, BRCA2, and CHEK2 mutation status. However, $\mathrm{CBC}$ incidence was not associated with reduced survival.
Although the majority of CBCs will be of equal or lower stage than the primary breast cancer, there may be an additive effect of having two cancers, perhaps resulting in lower survival rates. However, these results are mixed. Quan et $\mathrm{al}^{13}$ surmised that if the initial tumor grade is high stage, prognosis may be largely dictated by the initial cancer. However, two low stage cancers may result in a combined effect of each cancer and the vast majority of low stage index cancers also result in low stage CBC. Finally, since the widespread use of adjuvant therapies, the annual incidence of $\mathrm{CBC}$ has decreased and thus survival rates may now be greatly influenced by tumor biological characteristics and the receipt of effective adjuvant therapies.

\section{Contralateral prophylactic mastectomy and disease-free and overall survival}

Contralateral prophylactic mastectomy is estimated to reduce the risk of developing a CBC by approximately 94\%. ${ }^{7,13,28,29}$ Similarly, in a recent meta-analysis, focusing on patients with a personal history of unilateral breast cancer, Fayanju et $\mathrm{al}^{1}$ found that CPM was associated with a $96 \%$ reduction in metachronous $\mathrm{CBC}$. Although CPM reduces the risk of $\mathrm{CBC}$ among women with a history of breast cancer, population-based studies that have been conducted using both national and institutional databases to evaluate the effect of CPM on DFS or breast cancer survival and OS have shown conflicting results.

Some studies have shown a DFS benefit associated with CPM, but not an overall survival benefit. ${ }^{7,9}$ Using the SEER database, Bedrosian and $\mathrm{YaO}^{30}$ evaluated DFS benefit of CPM by patient and tumor characteristics, and showed that CPM was associated with improved breast cancer-specific survival. Patients younger than 50 years of age with Stage I or II ERnegative breast cancers had a $4.3 \%$ improvement in breast cancer survival compared to those who underwent CPM with ER-positive breast cancer, although use of adjuvant hormonal therapy was not included. Using an adjusted multivariable Cox regression analysis on patients from The University of Texas MD Anderson Cancer Center, Brewster et $\mathrm{al}^{31}$ showed a significant improvement in DFS (relative risk reduction of $25 \%$ ) for patients who underwent CPM compared with those who did not. The improved DFS was mostly seen among ER-negative patients compared with patients who were ERpositive. After a median follow-up time of 5 years, Yao et $\mathrm{al}^{3}$ estimated a statistically significant benefit from CPM, resulting in a relative risk reduction of $12 \%$ and 5-year absolute overall survival benefit of $2 \%$ using the National Cancer Database. Similar results were obtained when stratified by hormonal therapy use. 
A more recent analysis of women aged 45 years or less with Stage I or II breast cancer included in the National Cancer Database showed no overall survival benefit of CPM, and no benefit to ER-negative patients. ${ }^{32}$ Zeichner et al ${ }^{33}$ utilized data from patients at Mount Sinai Medical Center and found improved 10-year OS in women younger than 40 years, who are thought to be at greatest cumulative risk for secondary cancer. In a recent meta-analysis of existing studies, Fayanju et $\mathrm{al}^{1}$ found that although CPM decreases metachronous $\mathrm{CBC}$ in patients with $B R C A$ mutations and/or family history of breast cancer, it did not result in an overall or DFS benefit. These studies attempted to control for known confounders since patients who receive CPM are more likely to be white, younger than 50 years, and have certain characteristics that may predispose them to better outcomes. ${ }^{2,10}$

Possible disadvantages of CPM as a preventative treatment are the additional costs of surgery, ${ }^{34}$ and in patients who decided to undergo CPM, the majority elect to have bilateral reconstruction which is associated with increased morbidity. ${ }^{35}$ Frost et a ${ }^{36}$ reported that $27 \%$ of women had at least one unanticipated reoperation after CPM. Barton et al ${ }^{37}$ and Crosby et al ${ }^{38}$ reported that $27 \%-66 \%$ of women had at least one complication. This means that at least one-third of patients might not have experienced a surgical complication if they had not chosen CPM. Alternatively, several studies albeit retrospectively have shown overall high patient satisfaction with CPM and a low rate of regret among high risk women. ${ }^{36,39}$ Whether these psychosocial outcomes can be generalized to women at low-to-moderate risk of CBC is an active area of investigation.

\section{Decision analysis models of CPM}

Several decision analysis models have been conducted to determine life expectancy associated with CPM in comparison to surveillance alone. For high-risk groups, women with family history and/or $B R C A 1 / 2$ genetic mutation, prophylactic surgical procedures (eg, mastectomy) have been shown to be cost-effective when compared with surveillance in terms of life expectancy and QALYs. ${ }^{40-44}$ Life years can be adjusted by utilities or a qualitative evaluation of preferences for specific health states. One QALY represents a year in perfect health, with zero representing death. A year in any other intermediate state (eg, life after breast cancer or surgical treatment) would be some fraction of a QALY. Recently, Zendejas et $\mathrm{a}^{45}$ developed a Markov model to determine the survival, quality of life, and cost-effectiveness of CPM for patients with sporadic, early-stage breast cancers. CPM was cost-effective compared with surveillance for patients younger than age 70 . These results were sensitive to $B R C A$ $1 / 2$ mutation status and the assumption that the utility weights for the disease-free state for CPM was equal to or greater than that of surveillance.

A study conducted by Roberts et $\mathrm{a}^{35}$ also presented a cost-effectiveness analysis of CPM which incorporated risks due to reconstruction following ipsilateral and contralateral mastectomy. Their results showed a reduction in QALYs for CPM and were sensitive to the rate and methods of postmastectomy reconstruction and the cost of radiologic surveillance after unilateral mastectomy. The loss of QALYs may be due to the increased rates of complications associated with bilateral reconstruction. CPM was found to be cost saving for women younger than 50 years of age with sporadic, unilateral, early stage-breast cancer, but with reduced health benefits. Thus, CPM was not considered to be a cost-effective strategy for treatment. ${ }^{35}$ However, the authors' conjectured that potential QALYs gained may be more for an ER-negative patient, who has limited adjuvant treatment options, in comparison to a patient with an ER-positive tumor.

Most recently, Portschy et $\mathrm{l}^{6}$ presented a decision analysis using a Markov model to simulate survival outcomes after the decision to have or forgo CPM among patients with Stage I or II breast cancer without BRCA mutation. The absolute 20-year survival benefits from CPM were less than $1 \%$ among all age groups, ER status groups, and cancer stage patient groups with most gains seen for ER-negative patients who have a higher risk of developing $\mathrm{CBC}$. In fact, the benefit of CPM was lower for patients with Stage II compared with Stage I breast cancer because of worse prognosis associated with the primary breast cancer. ${ }^{6}$ The risk of distant metastatic disease from the index tumor outweighs the risk of CBC. ${ }^{31}$

\section{Nonsurgical options for contralateral breast cancer risk reduction}

The primary goals of systemic therapy for women with early stage breast cancer are to reduce the risk of local, regional, and distant recurrence and to improve survival. For women with an ER-positive breast cancer, an additional benefit of endocrine therapy is the reduction in the risk of developing $\mathrm{CBC}$. In the EBCTCG overview of randomized trials, tamoxifen use for 5 years substantially reduced the risk of $\mathrm{CBC}$ by $48 \%(P<0.00001)$ among women with ER-positive disease. This translated into a 3.2\% absolute risk reduction of CBC over 15 years (6.5\% versus 9.8\%) and was independent of age at diagnosis. ${ }^{24}$ These data demonstrated that a carry-over effect of $\mathrm{CBC}$ risk reduction persists up to 10 years after 
the discontinuation of tamoxifen. The ATLAS (adjuvant tamoxifen: longer against shorter) study which randomized women with early breast cancer who had completed 5 years of tamoxifen to either continue tamoxifen to 10 years or to stop at 5 years, showed a $3.7 \%$ absolute reduction in the risk of recurrence during years 5-14. ${ }^{46}$ Although the definition of the endpoint of recurrence included the development of $\mathrm{CBC}$, the $\mathrm{CBC}$ event was not reported separately and therefore the benefit of extended tamoxifen use on $\mathrm{CBC}$ risk is unclear. In the adjuvant setting, the aromatase inhibitors have also been shown to lower the risk of local regional and distant recurrence, and $\mathrm{CBC}$ in women with ER-positive breast cancers when compared to tamoxifen. ${ }^{47}$ In the 10 -year analysis of the ATAC (Arimidex, Tamoxifen, Alone or in Combination) trial, women randomized to receive anastrozole versus tamoxifen had a sustained statistically significant $32 \%$ reduction in $\mathrm{CBC} .{ }^{48}$ The absolute risk reduction of $\mathrm{CBC}$ for the anastrozole versus tamoxifen arms at 5 and 10 years of follow-up was $0.8 \%$ and $1.7 \%$ respectively. The extended adjuvant trial of letrozole versus placebo in women with early stage breast cancer who had completed 5 years of tamoxifen, estimated a statistically significant $42 \%$ reduction in the risk of $\mathrm{CBC}$ for those women receiving letrozole. ${ }^{49}$ There appears to be no superiority of the steroidal (eg, anastrozole) versus nonsteroidal (eg, exemestane) class of aromatase inhibitors on $\mathrm{CBC}$ risk when given as initial adjuvant therapy. ${ }^{50}$

Observational studies have demonstrated a reduced incidence of breast cancer among healthy women receiving bisphosphonate therapy for the prevention and treatment of bone loss. ${ }^{51-53}$ The Women's Health Initiative (WHI), showed that bisphosphonate use was associated with a $32 \%$ reduction $(P<0.01)$ in the incidence of invasive breast cancer after adjusting for potential confounders such as hip fracture prediction score (surrogate for bone mineral density), menopausal hormone replacement therapy, and breast cancer risk factors. ${ }^{51}$ Monsees et $\mathrm{al}^{54}$ conducted a nested case-control study among women diagnosed with a first primary ER-positive invasive breast cancer and showed that use of any nitrogenous bisphosphonate was associated with a $59 \%$ reduction in risk of $\mathrm{CBC}$ and the risk further declined with longer duration of bisphosphonate use. However, there have been several randomized studies evaluating the role of bisphosphonates in the adjuvant setting for reducing risk of recurrence; however, none of the trials showing a positive benefit on breast cancer DFS have reported a reduction in the risk of $\mathrm{CBC}$ associated with bisphosphonate use. ${ }^{55-57}$ Therefore, there is no indication for the use of bisphosphonate therapy for $\mathrm{CBC}$ risk reduction at this time.

\section{Limitations}

Although several population-based studies have been conducted to estimate risks of $\mathrm{CBC}$ and the benefit of CPM, these observational studies are not without limitations. Risks of CBC have been largely estimated using North American and European (specifically, Swedish) databases and institutions with their inherent limitations. For instance, SEER does not contain information on adjuvant hormonal therapy or comorbidities and there is incomplete data on Her $2 /$ neu status. Thus, regardless of techniques used to minimize bias, it is difficult to account for known prognostic and therapeutic variables. ${ }^{30}$ The National Cancer Database does not contain information regarding the development of $\mathrm{CBC}$ and it is not possible to estimate $\mathrm{CBC}$ incidence or breast cancer DFS. ${ }^{3}$ Limitations of prior epidemiologic studies evaluating the clinical benefit of CPM have included small sample sizes, short-term follow-up, as well as the aforementioned incomplete information on tumor characteristics, systematic treatment, and comorbidities. ${ }^{30}$ Finally, there is a diversity of information in the literature in terms of risks, rates, time period of measurement, and patient cohort of interest which can make interpretation of the data difficult for both clinicians and the general public.

\section{Conclusion}

The decision to have CPM continues to increase in popularity among women with unilateral breast cancer who have a low-to-moderate risk of developing a secondary cancer in the contralateral breast. Since it is highly unlikely that a randomized trial will ever be conducted to evaluate the clinical benefit of CPM, decision models that incorporate survival differences for particular subgroups can provide realistic estimates of the benefits of CPM and identify patient groups most likely to benefit. In addition, efforts should be made by health care providers to optimize breast conservation, minimize unnecessary tests, and improve patient education about their risk of $\mathrm{CBC}$ and the surgical complications associated with CPM and reconstruction for informed patientdecision making. ${ }^{8,35}$ Decision making tools that incorporate the results of $\mathrm{CBC}$ risk models and the effect of $\mathrm{CPM}$ and adjuvant endocrine therapy on $\mathrm{CBC}$ risk, DFS, and OS may be helpful in determining the best course of treatment for an individual patient.

\section{Acknowledgments}

The financial support for this study was provided by PatientCentered Outcomes Research Institute and National Cancer Institute grant R21 CA149803. The funding agreements 
ensured the authors' independence in study design, data interpretation, and writing of the paper.

\section{Disclosure}

The authors report no conflicts of interest in this work.

\section{References}

1. Fayanju OM, Stoll CR, Fowler S, Colditz GA, Margenthaler JA. Contralateral prophylactic mastectomy after unilateral breast cancer: a systematic review and meta-analysis. Ann Surg Oncol. 2014;260(6):1000-1010.

2. Stucky CC, Gray RJ, Wasif N, Dueck AC, Pockaj BA. Increase in contralateral prophylactic mastectomy: echoes of a bygone era? Surgical trends for unilateral breast cancer. Ann Surg Oncol. 2010;17(Suppl 3): 330-337.

3. Yao K, Winchester DJ, Czechura T, Huo D. Contralateral prophylactic mastectomy and survival: report from the National Cancer Data Base, 1998-2002. Breast Cancer Res Treat. 2013;142(3):465-476.

4. Nichols HB, Berrington de Gonzalez A, Lacey JV Jr, Rosenberg PS, Anderson WF. Declining incidence of contralateral breast cancer in the United States from 1975 to 2006. J Clin Oncol. 2011;29(12): $1564-1569$.

5. Lostumbo L, Carbine N, Wallace J, Ezzo J. Prophylactic mastectomy for the prevention of breast cancer. Cochrane Database Syst Rev. 2004; (4):CD002748.

6. Portschy PR, Kuntz KM, Tuttle TM. Survival outcomes after contralateral prophylactic mastectomy: a decision analysis. J Natl Cancer Inst. 2014;106(8).

7. Peralta EA, Ellenhorn JD, Wagman LD, Dagis A, Andersen JS, Chu DZ. Contralateral prophylactic mastectomy improves the outcome of selected patients undergoing mastectomy for breast cancer. Am J Surg. 2000;180(6):439-445.

8. King TA, Sakr R, Patil S, et al. Clinical management factors contribute to the decision for contralateral prophylactic mastectomy.J Clin Oncol. 2011;29(16):2158-2164.

9. Chung A, Huynh K, Lawrence C, Sim MS, Giuliano A. Comparison of patient characteristics and outcomes of contralateral prophylactic mastectomy and unilateral total mastectomy in breast cancer patients. Ann Surg Oncol. 2012;19(8):2600-2606.

10. Yi M, Hunt KK, Arun BK, et al. Factors affecting the decision of breast cancer patients to undergo contralateral prophylactic mastectomy. Cancer Prev Res. 2010;3(8):1026-1034.

11. Yadav BS, Sharma SC, Patel FD, Ghoshal S, Kapoor RK. Second primary in the contralateral breast after treatment of breast cancer. Radiother Oncol. 2008;86(2):171-176.

12. Lizarraga IM, Sugg SL, Weigel RJ, Scott-Conner CE. Review of risk factors for the development of contralateral breast cancer. Am J Surg. 2013;206(5):704-708.

13. Quan G, Pommier SJ, Pommier RF. Incidence and outcomes of contralateral breast cancers. Am J Surg. 2008;195(5):645-650; discussion 650.

14. Rosenberg SM, Tracy MS, Meyer ME, et al. Perceptions, knowledge, and satisfaction with contralateral prophylactic mastectomy among young women with breast cancer: a cross-sectional survey. Ann Intern Med. 2013;159(6):373-381.

15. Gao X, Fisher SG, Emami B. Risk of second primary cancer in the contralateral breast in women treated for early-stage breast cancer: a populationbased study. Int J Radiat Oncol Biol Phys. 2003;56(4):1038-1045.

16. Harvey EB, Brinton LA. Second cancer following cancer of the breast in Connecticut, 1935-1982. Natl Cancer Inst Monogr. 1985;68:99-112.

17. Schaapveld M, Visser O, Louwman WJ, et al. The impact of adjuvant therapy on contralateral breast cancer risk and the prognostic significance of contralateral breast cancer: a population based study in the Netherlands. Breast Cancer Res Treat. 2008;110(1):189-197.

18. Tuttle T, Habermann E, Abraham A, Emory T, Virnig B. Contralateral prophylactic mastectomy for patients with unilateral breast cancer. Expert Rev Anticancer Ther. 2007;7(8):1117-1122.
19. McLaughlin CC, Lillquist PP, Edge SB. Surveillance of prophylactic mastectomy: trends in use from 1995 through 2005. Cancer. 2009; 115(23):5404-5412.

20. Kollias J, Ellis IO, Elston CW, Blamey RW. Clinical and histological predictors of contralateral breast cancer. Eur J Surg Oncol. 1999;25(6): 584-589.

21. Robbins GF, Berg JW. Bilateral primary breast cancer: a prospective clinicopathological study. Cancer. 1964;17:1501-1527.

22. Healey EA, Cook EF, Orav EJ, Schnitt SJ, Connolly JL, Harris JR. Contralateral breast cancer: clinical characteristics and impact on prognosis. J Clin Oncol. 1993;11(8):1545-1552.

23. Rosen PP, Groshen S, Kinne DW, Hellman S. Contralateral breast carcinoma: an assessment of risk and prognosis in stage I (T1N0M0) and stage II (T1N1M0) patients with 20-year follow-up. Surgery. 1989;106(5):904-910.

24. Davies C, Godwin J, Gray R, et al. Relevance of breast cancer hormone receptors and other factors to the efficacy of adjuvant tamoxifen: patientlevel meta-analysis of randomised trials. Lancet. 2011;378(9793): 771-784.

25. Hankey BF, Curtis RE, Naughton MD, Boice JD Jr, Flannery JT. A retrospective cohort analysis of second breast cancer risk for primary breast cancer patients with an assessment of the effect of radiation therapy. J Natl Cancer Inst. 1983;70(5):797-804.

26. Carmichael AR, Bendall S, Lockerbie L, Prescott R, Bates T. The long-term outcome of synchronous bilateral breast cancer is worse than metachronous or unilateral tumours. Eur J Surg Oncol. 2002;28(4): 388-391.

27. Verkooijen HM, Chatelain V, Fioretta G, et al. Survival after bilateral breast cancer: results from a population-based study. Breast Cancer Res Treat. 2007;105(3):347-357.

28. Narod SA. Bilateral breast cancers. Nat Rev Clin Oncol. 2014;11(3): 157-166.

29. McDonnell SK, Schaid DJ, Myers JL, et al. Efficacy of contralateral prophylactic mastectomy in women with a personal and family history of breast cancer. J Clin Oncol. 2001;19(19):3938-3943.

30. Bedrosian I, Yao K. Contralateral prophylactic mastectomy and survival: an ongoing challenge. Ann Surg Oncol. 2014;21(11):3372-3374.

31. Brewster A, Bedrosian I, Parker P, et al. Association between contralateral prophylactic mastectomy and breast cancer outcomes by hormone receptor status. Cancer. 2012;118(22):5637-5643.

32. Pesce C, Liederbach E, Wang C, Lapin B, Winchester DJ, Yao K. Contralateral prophylactic mastectomy provides no survival benefit in young women with estrogen receptor-negative breast cancer. Ann Surg Oncol. 2014;21(10):3231-3239.

33. Zeichner SB, Zeichner SB, Ruiz AL, Markward NJ, Rodriguez E. Improved long-term survival with contralateral prophylactic mastectomy among young women. Asian Pac J Cancer Prev. 2014;15(3): $1155-1162$.

34. Deshmukh AA, Cantor SB, Crosby MA, et al. Cost of contralateral prophylactic mastectomy. Ann Surg Oncol. 2014;21(9):2823-2830.

35. Roberts A, Habibi M, Frick KD. Cost-effectiveness of contralateral prophylactic mastectomy for prevention of contralateral breast cancer. Ann Surg Oncol. 2014;21(7):2209-2217.

36. Frost MH, Hoskin TL, Hartmann LC, Degnim AC, Johnson JL, Boughey JC. Contralateral prophylactic mastectomy: long-term consistency of satisfaction and adverse effects and the significance of informed decision-making, quality of life, and personality traits. Ann Surg Oncol. 2011;18(11):3110-3116.

37. Barton MB, West CN, Liu IL, et al. Complications following bilateral prophylactic mastectomy. J Natl Cancer Inst Monogr. 2005;(35): 61-66.

38. Crosby MA, Garvey PB, Selber JC, et al. Reconstructive outcomes in patients undergoing contralateral prophylactic mastectomy. Plast Reconstr Surg. 2011;128(5):1025-1033.

39. Montgomery LL, Tran KN, Heelan MC, et al. Issues of regret in women with contralateral prophylactic mastectomies. Ann Surg Oncol. 1999; 6(6):546-552. 
40. van Roosmalen MS, Verhoef LC, Stalmeier PF, Hoogerbrugge N, van Daal WA. Decision analysis of prophylactic surgery or screening for BRCA1 mutation carriers: a more prominent role for oophorectomy. J Clin Oncol. 2002;20(8):2092-2100.

41. Grann VR, Jacobson JS, Thomason D, Hershman D, Heitjan DF, Neugut AI. Effect of prevention strategies on survival and qualityadjusted survival of women with BRCA1/2 mutations: an updated decision analysis. J Clin Oncol. 2002;20(10):2520-2529.

42. Schrag D, Kuntz KM, Garber JE, Weeks JC. Life expectancy gains from cancer prevention strategies for women with breast cancer and BRCA1 or BRCA2 mutations. JAMA. 2000;283(5):617-624.

43. Anderson K, Jacobson JS, Heitjan DF, et al. Cost-effectiveness of preventive strategies for women with a BRCA1 or a BRCA2 mutation. Ann Intern Med. 2006;144(6):397-406.

44. Grann VR, Jacobson JS, Whang W, et al. Prevention with tamoxifen or other hormones versus prophylactic surgery in BRCA1/2-positive women: a decision analysis. Cancer J Sci Am. 2000;6(1):13-20.

45. Zendejas B, Moriarty JP, O’Byrne J, Degnim AC, Farley DR, Boughey JC. Cost-effectiveness of contralateral prophylactic mastectomy versus routine surveillance in patients with unilateral breast cancer. J Clin Oncol. 2011;29(22):2993-3000.

46. Davies C, Pan H, Godwin J, et al. Long-term effects of continuing adjuvant tamoxifen to 10 years versus stopping at 5 years after diagnosis of oestrogen receptor-positive breast cancer: ATLAS, a randomised trial. Lancet. 2013;381(9869):805-816.

47. Schneider R, Barakat A, Pippen J, Osborne C. Aromatase inhibitors in the treatment of breast cancer in post-menopausal female patients: an update. Breast Cancer. 2011;3:113-125.

48. Cuzick J, Sestak I, Baum M, et al. Effect of anastrozole and tamoxifen as adjuvant treatment for early stage breast cancer: 10-year analysis of the ATAC trial. Lancet Oncology. 2010;11(12):1135-1141.
49. Goss PE, Ingle JN, Martino S, et al. Randomized trial of letrozole following tamoxifen as extended adjuvant therapy in receptor-positive breast cancer: updated findings from NCIC CTG MA.17. J Natl Cancer Inst. 2005;97(17):1262-1271.

50. Goss PE, Ingle JN, Pritchard KI, et al. Exemestane versus anastrozole in postmenopausal women with early breast cancer: NCIC CTG MA.27-a randomized controlled phase III trial. J Clin Oncol. 2013;31(11): 1398-1404.

51. Chlebowski RT, Chen Z, Cauley JA, et al. Oral bisphosphonate use and breast cancer incidence in postmenopausal women. J Clin Oncol. 2010;28(22):3582-3590.

52. Robbins J, Aragaki AK, Kooperberg C, et al. Factors associated with 5-year risk of hip fracture in postmenopausal women. JAMA. 2007; 298(20):2389-2398.

53. Rennert G, Pinchev M, Rennert HS. Use of bisphosphonates and risk of postmenopausal breast cancer. J Clin Oncol. 2010;28(22): 3577-3581.

54. Monsees GM, Malone KE, Tang MT, Newcomb PA, Li CI. Bisphosphonate use after estrogen receptor-positive breast cancer and risk of contralateral breast cancer. J Natl Cancer Inst. 2011;103(23):1752-1760.

55. Gnant M, Mlineritsch B, Stoeger H, et al. Adjuvant endocrine therapy plus zoledronic acid in premenopausal women with early-stage breast cancer: 62-month follow-up from the ABCSG-12 randomised trial. Lancet Oncol. 2011;12(7):631-641.

56. Paterson AH, Anderson SJ, Lembersky BC, et al. Oral clodronate for adjuvant treatment of operable breast cancer (National Surgical Adjuvant Breast and Bowel Project protocol B-34): a multicentre, placebocontrolled, randomised trial. Lancet Oncol. 2012;13(7):734-742.

57. Aft RL, Naughton M, Trinkaus K, Weilbaecher K. Effect of (neo) adjuvant zoledronic acid on disease-free and overall survival in clinical stage II/III breast cancer. Br J Cancer. 2012;107(1):7-11.
International Journal of Women's Health

\section{Publish your work in this journal}

The International Journal of Women's Health is an international, peerreviewed open-access journal publishing original research, reports, editorials, reviews and commentaries on all aspects of women's healthcare including gynecology, obstetrics, and breast cancer. The manuscript management system is completely online and includes

\section{Dovepress}

a very quick and fair peer-review system, which is all easy to use. Visit http://www.dovepress.com/testimonials.php to read real quotes from published authors. 